\title{
Study of CoFe2O4 particles synthesized with various concentrations of PVP polymer
}

\begin{abstract}
$\mathrm{CoFe} 2 \mathrm{O} 4$ particles were synthesized using metallic nitrates and polyvinylpyrolidone (PVP) using sol-gel method followed by calcination for $2 \mathrm{~h}$ at $960 \mathrm{C}$. PVP performed as a surfactant and the effect of various concentrations of PVP on the resultant $\mathrm{CoFe} 2 \mathrm{O} 4$ powder was studied. The resultant samples were characterized by XRD, TG/DSC, HR-SEM and VSM. Xray diffraction results indicated the crystalline phase of $\mathrm{CoFe} 2 \mathrm{O} 4$ particles and impurity phase of hematite was observed for higher PVP concentrations. SEM images demonstrated the influence of PVP concentration on the size of the particles. By VSM measurements, the variations in magnetic properties with respect to PVP concentration are studied. All the magnetic characteristics $\mathrm{H} \mathrm{c}, \mathrm{M}$ s and $\mathrm{M} \mathrm{r}$ increased for $6 \mathrm{wt} \%$ and $15 \mathrm{wt} \%$ of PVP concentration. The CoFe $2 \mathrm{O} 4$ particles synthesized with the optimum concentration of PVP may be very attractive for potential applications because of their outstanding magnetic properties ( $\mathrm{M} \mathrm{s}=81.1 \mathrm{Am} 2 / \mathrm{kg}, \mathrm{H} \mathrm{c}=831$ Gauss).
\end{abstract}

Keyword: Chemical synthesis; Magnetic materials; Magnetic properties; Thermogravimetric analysis (TGA) 